\title{
EXPERIMENTS ON A SNOW-PATCH IN THE MOUNTAINS OF SWEDEN
}

\author{
By I. Y. Ashwell \\ (Department of Geography, University of Alberta, Calgary, Alberta, Canada) \\ and F. G. HANNELL \\ (Department of Geography, McMaster University, Hamilton, Ontario, Canada)
}

\begin{abstract}
Investigations into the mechanism of dirt-cone formation, and snow patterning, are described. In each case the changes in patches of various materials arranged on a snow surface, were observed over a period of three weeks in the summer, under varying weather conditions. The effects of fine rock flour on the formation of dirt cones are analysed. Two main weather types are recognized as having different, but important, effects on the surface features of the snow; föhn-type winds, and calm, sunny conditions.

RÉsumé. Cet article décrit les investigations concernant le mécanisme de formation de cônes de poussières et de formes superficielles de neige. Les observations s'étendent sur 3 semaines en été, sous des conditions météorologiques variables. Dans les 2 cas on a observé les variations de surface de matériaux divers disposés sur la neige. L'effet de sable fin (rock flour) sur la formation de cônes de poussières a été analysé. On a constaté que 2 types principaux de temps avaient une influence différente, mais importante, sur les caractères de la surface de neige: (a) les vents de type foehn (b) le temps calme et ensoleillé.
\end{abstract}

Zusammenfassung. Untersuchungen über den Mechanismus der Bildung (a) von Ablationskegeln und (b) von Mustern auf Schneeoberflächen werden beschrieben. Bei jedem Versuch wurden die Veränderungen an Proben verschiedenen Materials, die auf einer Schneefläche ausgelegt worden waren, innerhalb einer Periode von 3 Sommerwochen unter wechselnden Wetterbedingungen beobachtet. Die Auswirkung feinen Felssandes auf die Bildung von Ablationskegeln wird untersucht. Zwei Haupt-Wettertypen beeinflussten die Schneeoberfläche besonders stark, wenn auch mit verschiedenen Wirkungden: (a) föhnartige Winde und (b) Windstille mit Sonneneinstrahlung.

\section{INTRODUCTION}

During August and early September 1959, the members of the British Schools Exploring Society's Expedition undertook various detailed studies in the neighbourhood of the Sarek mountains in Sweden. The meteorological and glaciological parties worked mainly in the Paktesjokk valley (lat. $67^{\circ} \mathrm{I} \mathrm{o}^{\prime} \mathrm{N}$., long. I $7^{\circ} 5^{\prime} \mathrm{E}$ E.), which was the only outlet for water and cold air from a broad basin, the diameter of which was about $2 \mathrm{~km}$. (Fig. I).

A snow-patch which lay along the valley floor, had a length of about $\mathrm{I} \mathrm{km}$. and a maximum width of about $100 \mathrm{~m}$. At the beginning of August the Paktesjokk stream flowed beneath this snow-patch but, as melting progressed, holes appeared in a number of places. On the surface of the snow-patch a group of dirt cones (at A in Fig. I) occupied a strip about $50 \mathrm{~m}$. long which ran parallel to the valley sides. The material covering these cones was very fine rock flour, which was dark brown in colour (Fig. 2). It was probably deposited by the stream during a period in which its tunnel beneath the snow-patch was blocked. An almost identical set of circumstances has been reported from Iceland (Bout, I957, p. I o6).

The dirt cones lay in an oval trough, sharply cut into the surface of the snow-patch and about $2 \mathrm{~m}$. in maximum depth. Away from the cones, the snow surface in this trough was thinly covered by rock flour, whilst the surface of the snow-patch elsewhere had a very thin, irregular and much more varied covering of vaccinium leaves, conifer needles and some reindeer droppings. A close patterning by ablation polygons was general over the whole surface of the snow-patch (Fig. 3), and also on all exposed under-surfaces (Fig. 4).

Certain investigations were made concerning the formation of dirt cones and ablation polygons, and these are described below.

\section{DirT Cones}

The dirt cones varied in height from $0.5 \mathrm{~m}$. to $\mathrm{I} \cdot 5 \mathrm{~m}$., and their sides sloped at angles of $5^{\circ}$ to $60^{\circ}$. Little change was noted during the month in which they were under observation, 


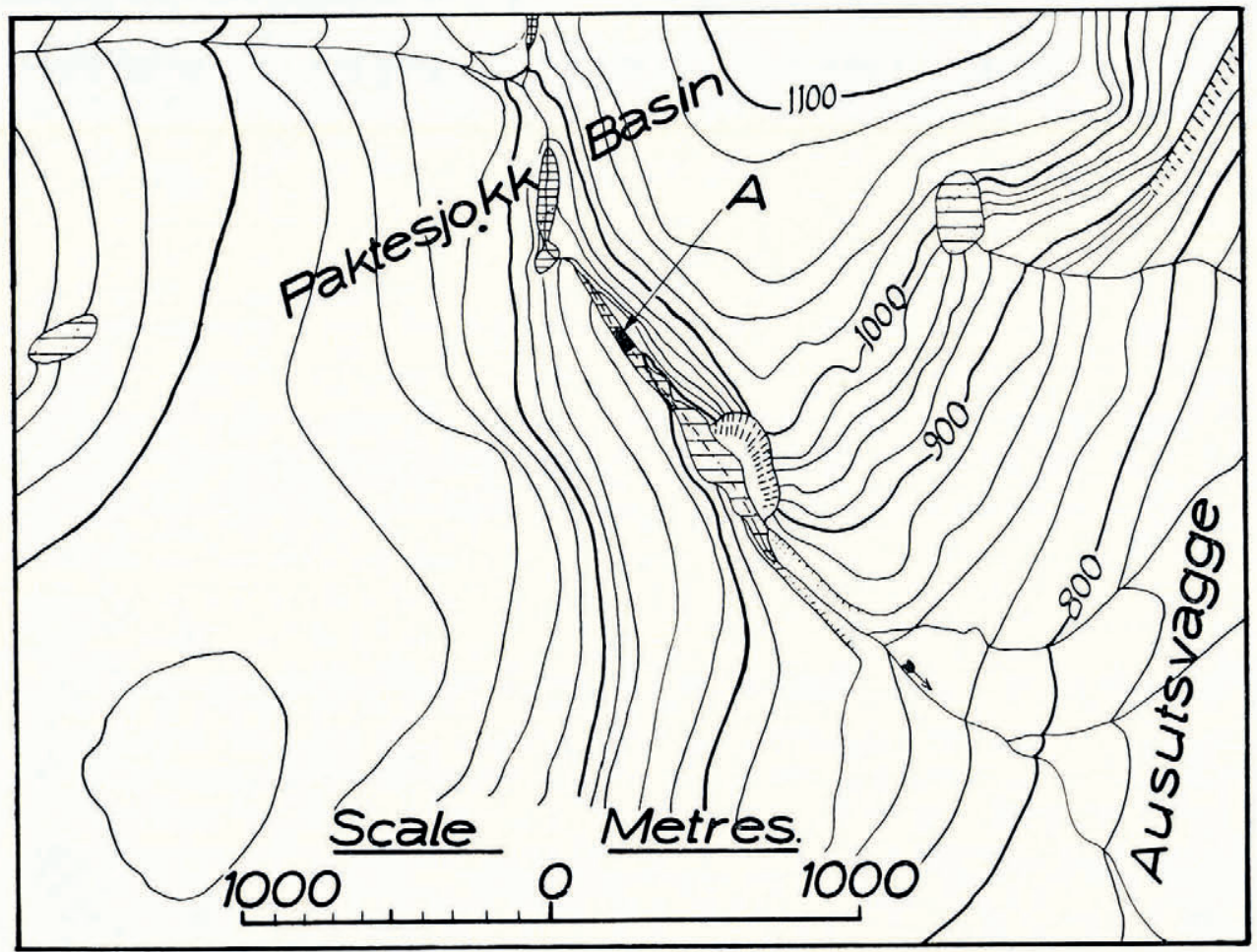

Fig. I. Experiments were carried out at A. Snow patches are indicated by horizontal shading. North is at the top of the map

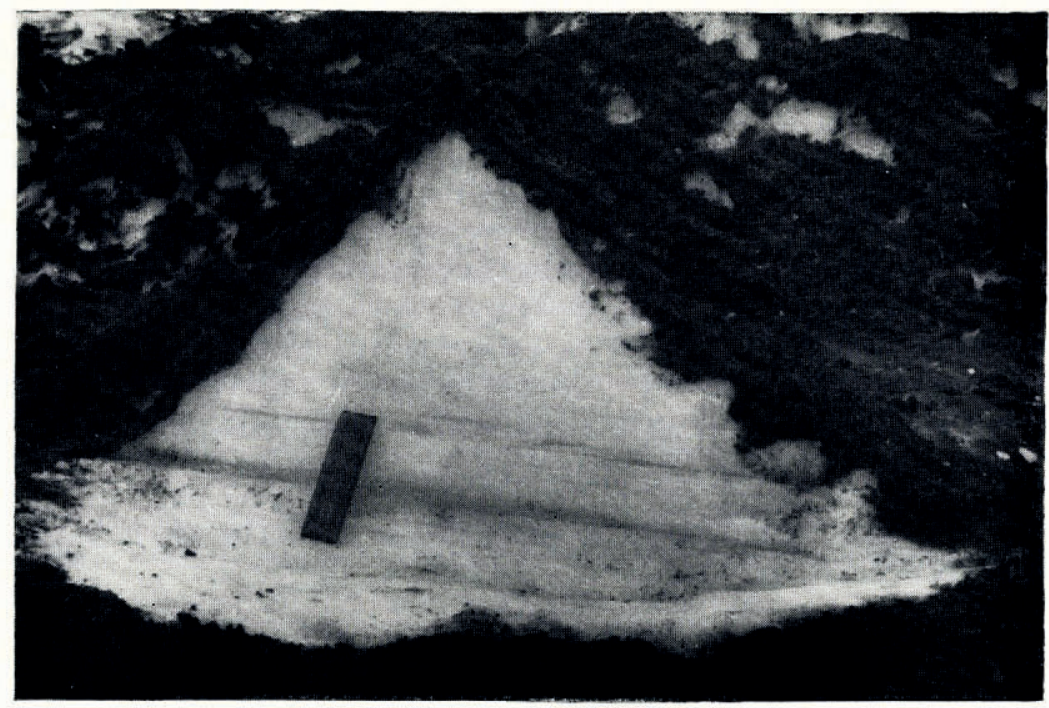

Fig. 2. One of the smaller dirt cones, sectioned and viewed from the south-east 
except for some general increase in height due to the lowering of the surface of the oval trough in those places where the dirt covering was thinnest. Elsewhere, the main surface of the snow-patch was lowered by about $0.5 \mathrm{~m}$. In places, the stream course beneath the cones became exposed, but in a number of cases the cones were sufficiently strong to support themselves as bridges.

Sections were cut through several cones, and in each case the material was found to consist of hard-packed and slightly granular snow (Fig. 2). It seems certain that any summer

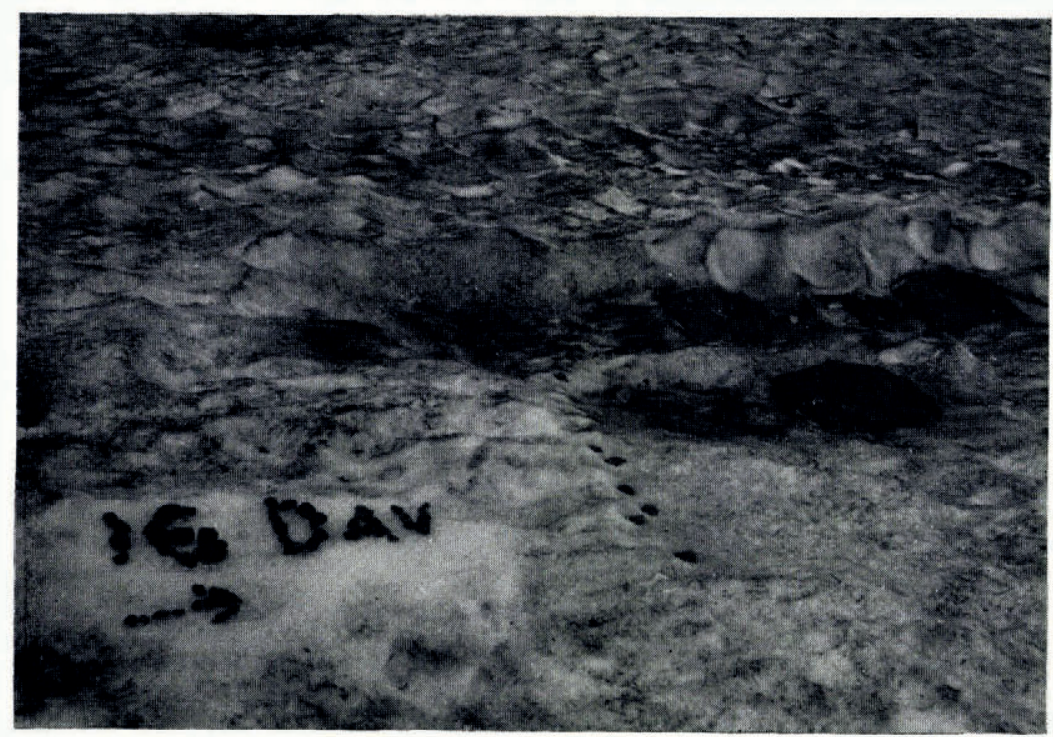

Fig. 3. The experimental site on the 16 th day. The dirt squares lie in a trench below the heavily patterned snow surface

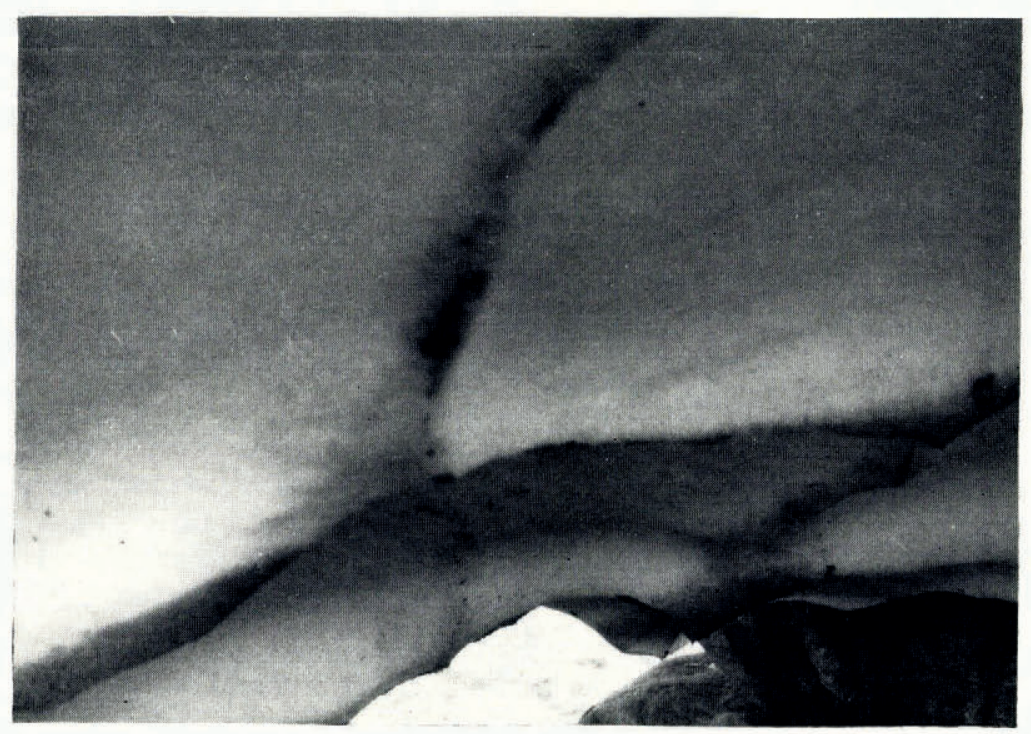

Fig. 4. Ablation polygons on the under-surface of the snow-patch, showing edges darkened by melting 
snow-patch in this area would acquire at least a thin covering of dirt. Hence the complete absence of dirt within the interiors of the cones strongly suggests that these were formed of snow which had fallen during the preceding winter.

An experimental plot, whose surface was cleared of debris and scraped flat, was laid out within the oval trough which contained the cones, and on this plot four squares of the dark brown rock flour were carefully laid. Their sides were $30 \mathrm{~cm}$. in length, and the thickness of the covering of rock flour was 2, 5, io and $25 \mathrm{~mm}$. respectively.

During the first four days these squares were inspected in detail and photographed at $24-\mathrm{hr}$. intervals. No observations were possible on days five to seven inclusive owing to the absence of the glaciologists who were then at work elsewhere. During days eight to ten, a blizzard entirely buried the experimental squares with snow, but after this had melted sufficiently by day twelve, further observations were made until day eighteen.

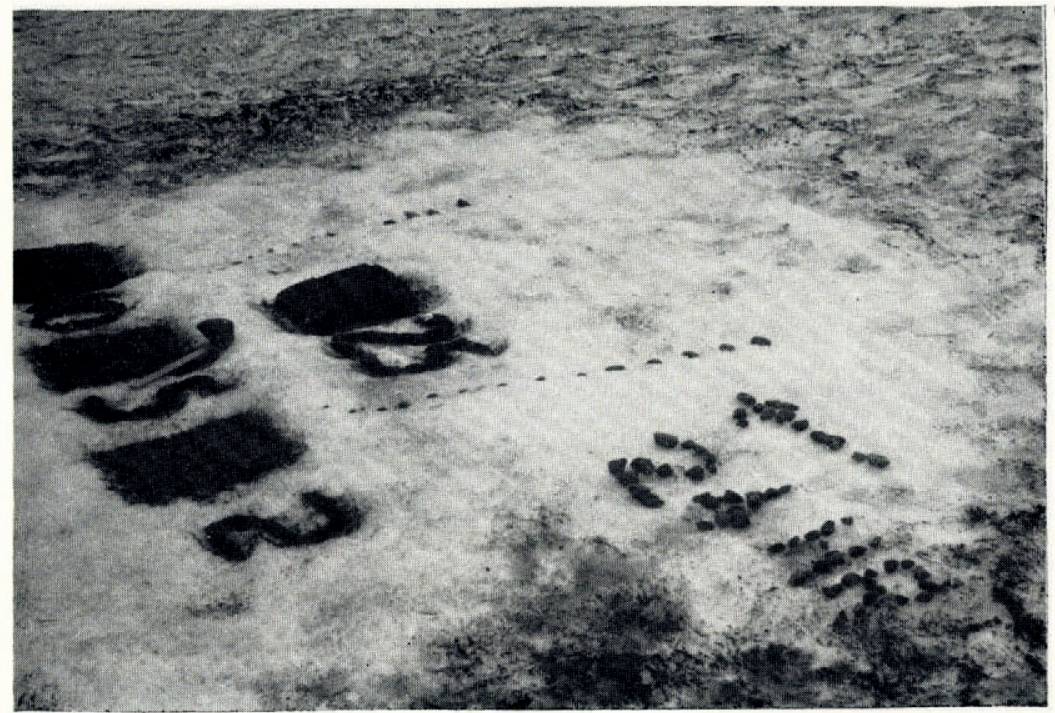

Fig. 5. The dirt squares after $24 \mathrm{hr}$. The arrow shows the direction of the down-valley wind which prevailed throughout this period

The most striking changes occurred during the first $24 \mathrm{hr}$. (Fig. 5). The general level of the surface of the experimental plot had been slightly lowered, but around the dirt squares two different processes had been at work:

(I) The tops of the io and $25 \mathrm{~mm}$. squares now stood slightly above the general level of the surface, whilst those of the 5 and $2 \mathrm{~mm}$. squares lay about $5 \mathrm{~mm}$. below this level.

(2) On all but the leeward sides of the two most thickly covered squares, trenches had appeared. In the case of the $25 \mathrm{~mm}$. square these trenches were about $25 \mathrm{~mm}$. $\times 25 \mathrm{~mm}$. in section, whilst those which were associated with the $10 \mathrm{~mm}$. square measured about $\mathrm{I}_{5} \mathrm{~mm}$. $\times \mathrm{I}_{5} \mathrm{~mm}$. Rows of pebbles of varying size had been placed alongside the $25 \mathrm{~mm}$. square (Fig. 5), and it was noticed that each of these, down to $2 \mathrm{~cm}$. in diameter, had developed on its windward side a scoop in the snow of depth roughly equal to the diameter of the associated pebble.

The wind throughout this first $24 \mathrm{hr}$. period had been strong and down-valley in direction, and the Campbell-Stokes sunshine recorder, located at the top of the valley-side to the north-east, showed only one very slight burn. The meteorological chart for this period showed 
that the experimental area lay in the warm sector of a depression, and the construction of a tephigram, from information kindly supplied by the Meteorologiske Institutjoner i Norge, clearly indicated that the down-valley wind was of föhn type.

During the succeeding three days there were long periods of sunshine with virtually no wind. Temperatures were high and humidities low, and under the influence of these changed meteorological conditions the embryo features on the experimental plot were affected by different processes. After the lapse of $48 \mathrm{hr}$., the pebbles arranged parallel to two sides of the $25 \mathrm{~mm}$. square had begun to sink into the snow surface (Fig. 6) instead of lying on the surface

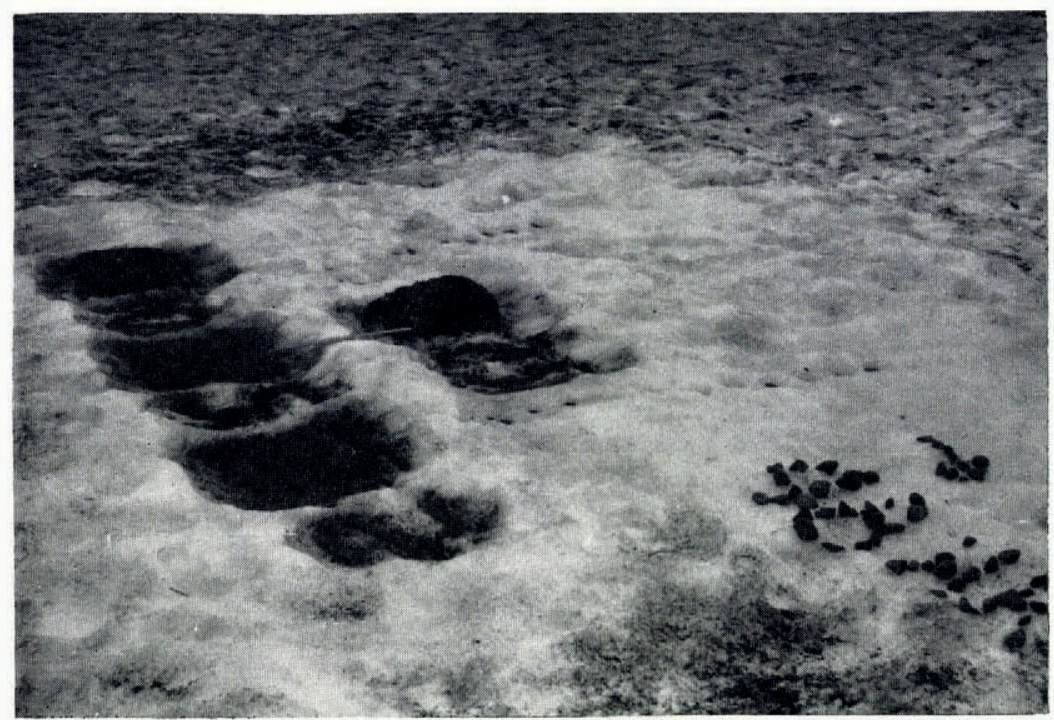

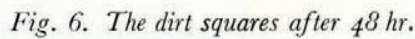

with scoops on their windward sides as had been the case on the first day of observation. Ablation polygons now began to develop over the surface of the experimental area, and these seemed to be due to melting beneath small and very thin deposits of wind-blown material which had accumulated on the preceeding day. The trenches on three sides of each of the two thicker dirt squares had by now been enlarged outwards to form deep and rounded hollows about $4 \mathrm{~cm}$. deep, the junctions of which with the surface of the experimental area were now somewhat confused in contrast to the sharp edges noted on the first day. The dirt on these two more thickly covered squares was now very wet, and it showed a tendency to sludge down into the hollows. Meanwhile, the surfaces of the two more thinly covered squares now lay some $2 \mathrm{~cm}$. below the general level of the surface.

After $96 \mathrm{hr}$. the general drop in the level of the snow surface was more marked, and the most thickly covered square of dirt was now definitely rounded in outline (Fig. 7). Its core was very hard, but its top still stood only a little above the general level of the experimental plot. The two more thinly covered squares had coalesced into a trench whose floor lay about $6 \mathrm{~cm}$. below this same general level. It was at this time that the relief of the four dirt squares attained its maximum amplitude.

In the blizzard which followed, the four dirt squares were covered by snow, and when they first reappeared on day 12 the covering of dirt was in each case frozen hard. The amplitude of the $25 \mathrm{~mm}$. square had been considerably reduced, possibly because the dirt covering had first frozen and then dried, allowing some of it to be carried away by the wind. 
During the succeeding four days, long periods of sunshine brought higher temperatures. As a result of further melting, the square which had been covered with $2 \mathrm{~mm}$. of dirt had almost disappeared by day 16 , and the four squares lay in a trench about $12 \mathrm{~cm}$. deep (Fig. 3).

The above observations point to the following conclusions:

(I) Strong winds, and especially those of föhn type, can, in the absence of insolation, cut a well marked scoop on the up-wind side of an object. The depth of such a scoop is of the same order of magnitude as the height of the object.

(2) Under the same conditions, a thin patch of dirt will melt downwards into a snow surface in spite of the absence of insolation.

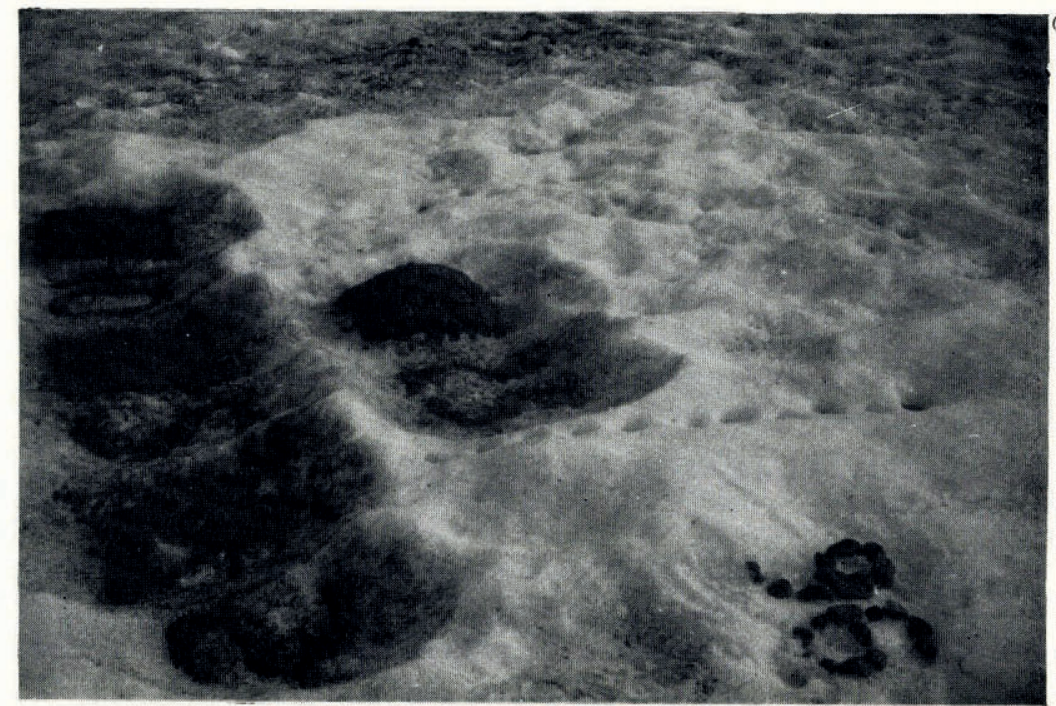

Fig. 7. The dirt squares after $96 \mathrm{hr}$.

(3) The oval-shaped hollow in which the collection of natural dirt cones lay was probably formed in the same way as that smaller hollow which eventually contained the four experimental squares of dirt.

(4) It has long been established (e.g. Swithinbank, I950, p. 464) that a layer of darkcoloured dirt of less than a certain thickness melts the underlying snow whilst a thicker layer protects it. In the case under review a $10 \mathrm{~mm}$. thickness was sufficient to maintain approximate equilibrium between melting and protection, whilst a $25 \mathrm{~mm}$. layer certainly protected.

\section{Ablation Polygons}

\section{On the surface}

A second experimental plot was prepared at the same time as, and close to, the four dirt squares, on a gently sloping area of cleared snow facing north-east (Fig. 8). Some of the vegetation debris found on the snow surface was collected and laid down in the form of four strips, one pair aligned up-and-down valley, shown horizontal in the photograph, with the other pair at right angles. Each strip was $30 \mathrm{~cm}$. long. The highest pair of strips, which lay furthest from the camera, were formed from light-coloured material which was laid more 
thickly, whilst the material of the more thinly-spread lower pair was quite black. A trench about $\mathrm{s} 5 \mathrm{~cm}$. in section was cut on the lower side of the experimental plot and floored with stones.

At the end of the first 24-hr. period, during which time scoops had been cut on all but the leeward sides of the two more thickly covered dirt squares, changes were also noted in the immediate vicinity of the four strips (Fig. 9). The thicker of the two strips which lay parallel to the down-valley wind direction (furthest from the camera in Fig. 9), was raised slightly, whilst the thinner one which lay in the same direction was definitely lowered. Each of the two strips which lay at right angles to the wind direction had developed a scoop on its up-wind side. The trench containing the stones had been opened out and its edges sharpened, whilst its sides, which had hitherto been smooth, were now interrupted by the development of ablation polygons (Richardson and Harper, 1957). Dirt had collected both on the ridges between

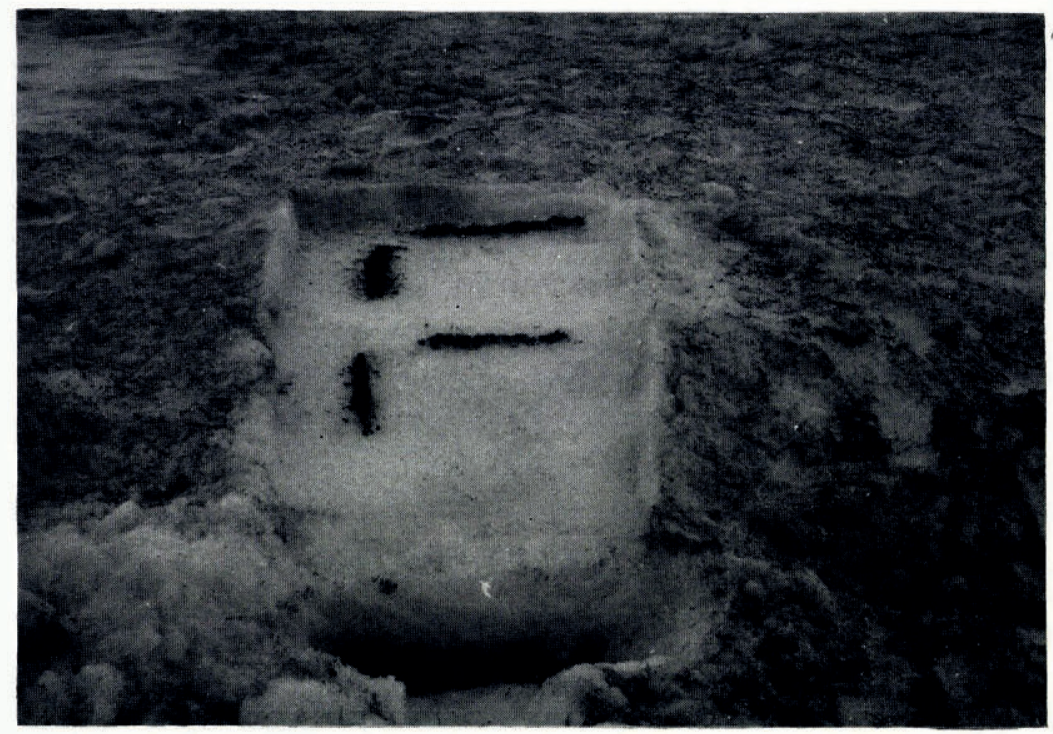

Fig. 8. The dirt strips as laid down

adjacent ablation polygons and on the edges of the trench (Fig. 9). Any upstanding snow surfaces had been considerably smoothed, and a comparison of Figures 8 and 9 shows that the general supply of dirt, which had been increased under the influence of the down-valley wind, seemed to be concentrated mainly on such upstanding surfaces as lay at right angles to the wind direction.

During the succeeding $24 \mathrm{hr}$. period, in which warm and sunny conditions prevailed, each of the strips underwent changes of a different nature. Thus, after the lapse of $48 \mathrm{hr}$., Figure Io shows that the two more thinly covered strips, lying nearest to the camera, were sinking into the surface, and that local melting and refreezing had darkened the colour of the resulting hollows. A hollow had also been formed beneath the next highest strip, but the topmost strip, which had lain parallel to the wind direction throughout the first day, remained comparatively undisturbed.

Under the influence of similar weather conditions on the third and fourth days the melting process continued, and the whole surface of the strip-plot became interrupted by the development of ablation polygons. By the end of the fourth day the strips were almost unrecognizable (Fig. I I) and a strong pattern of ablation polygons had evolved. 
It would thus appear that two processes are involved in the formation of ablation polygons:

(a) Under cloudy and windy conditions, concentrations of dirt, especially those lying at right angles and thus presenting a considerable surface to the wind, are undercut by the development of small trenches on the windward side. It has been reported from Mikkaglaciären, about $25 \mathrm{~km}$. from the site of the experiments here discussed, that, when winds were fairly strong, ablation polygons developed such that their long axes

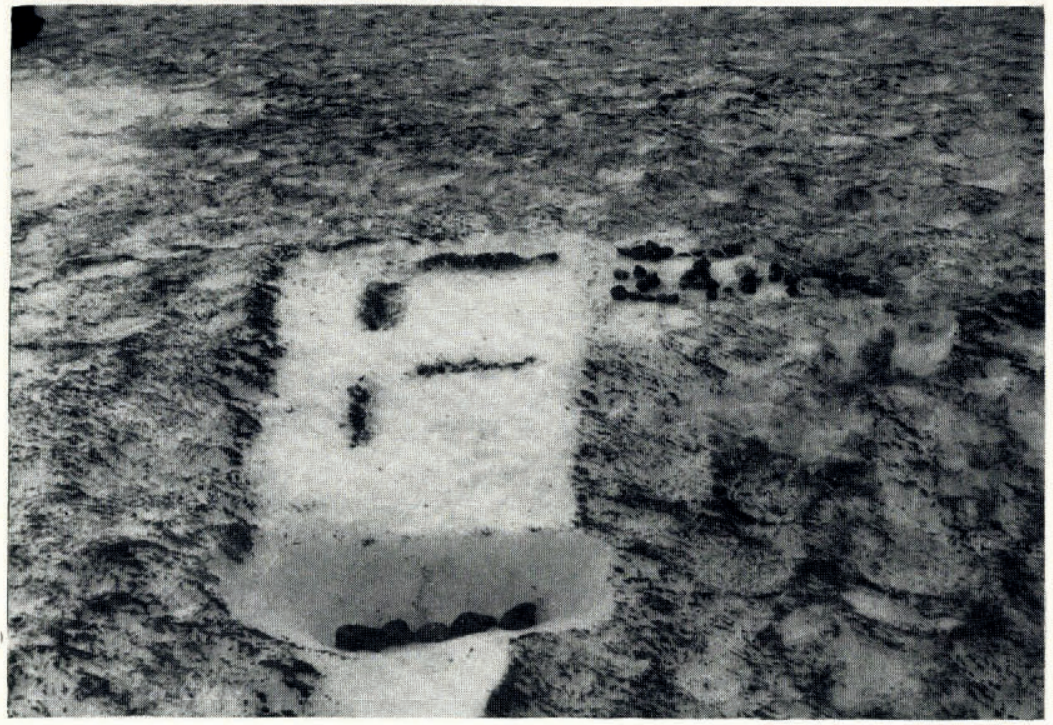

Fig. 9. The dirt strips after $24 \mathrm{hr}$.

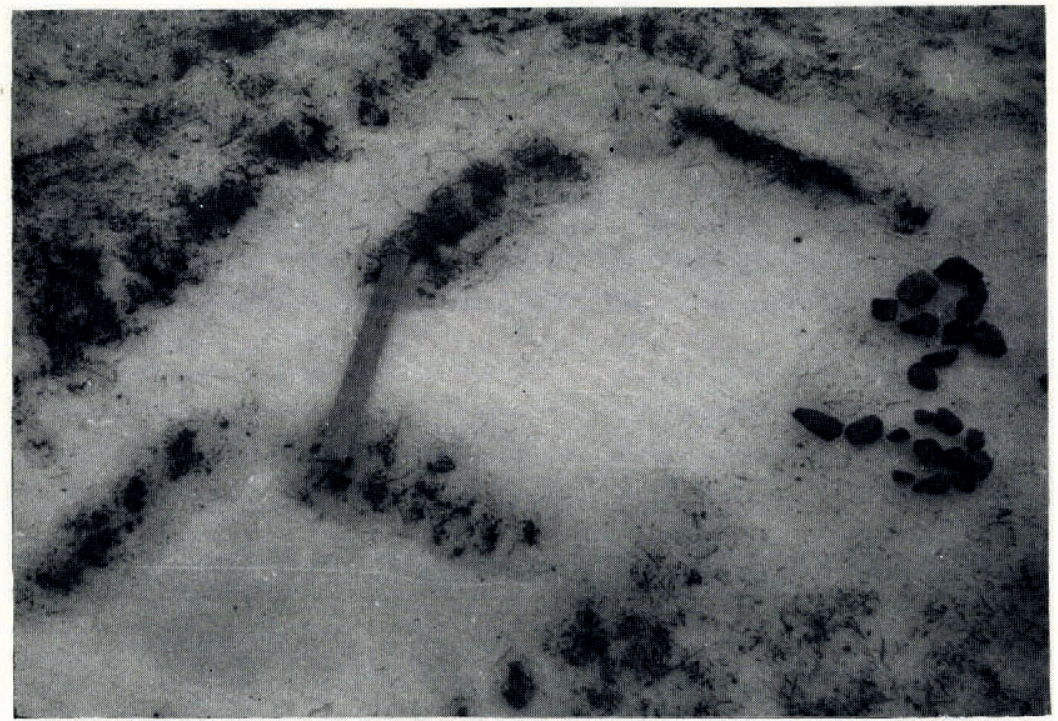

Fig. 10. The dirt-strip area after $4^{8} \mathrm{hr}$. 
ran at right angles to the wind direction (Sjödin, I957, p. 6r ). The evidence therefore suggests that under cloudy and windy conditions ablation polygons and dirt cones begin to form under the action of the same process, and that this is not connected with the theory of "normal trajectory" as postulated by Ball (1954).

(b) Under the influence of warm sunny weather, hollows are melted in the snow surface and particularly beneath thin accumulations of dirt which tend to be dispersed in the hollows. Under the later influence of strong winds, the material dispersed at the bottoms of hollows would tend to be concentrated again at right angles to the wind direction, and either blown on to the ridges or be so undercut that hollows form on the windward side. This would result in a sharp-edged pattern, in distinction to the

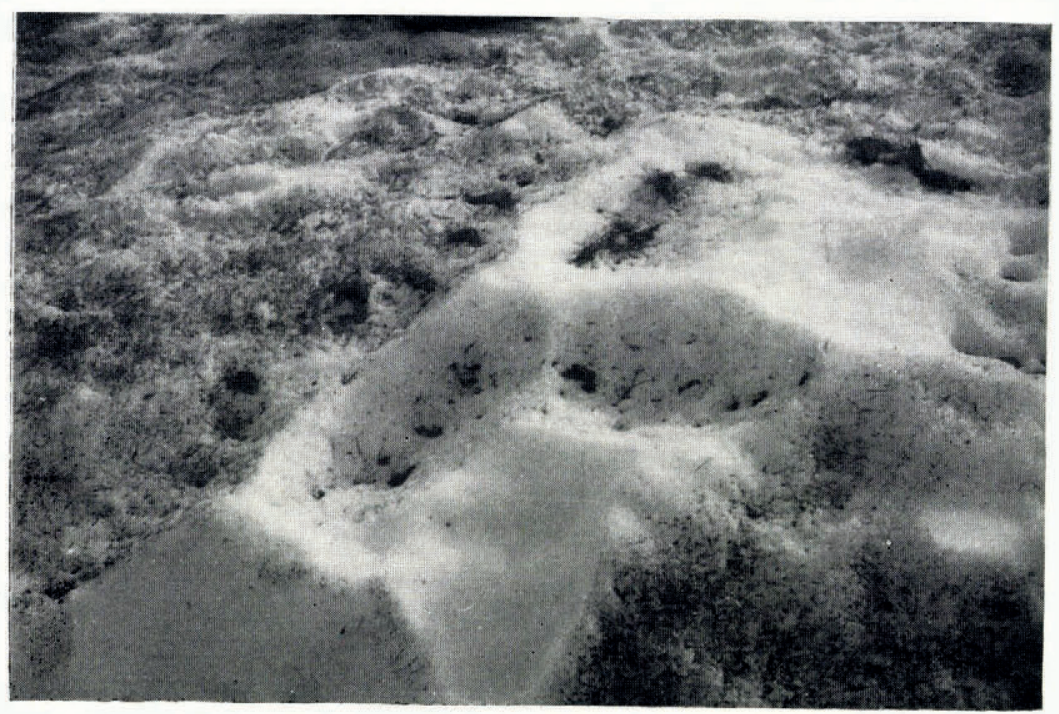

Fig. 11. The dirt-strip area after $96 \mathrm{hr}$.

windless days when melting leads to a softening of outlines. The lines of dirt running parallel to the wind direction appear to be a more permanent feature of the patterning, whilst those at right angles tend to change more quickly.

\section{On under-surfaces}

Under-surface ablation polygons were well developed in many places, especially on the roof of the tunnel which the stream had excavated beneath the snow patch (Fig. 4). The edges of these polygons were sharp and covered with dirt, but the generally darker colour along them was clearly due to melting. Any moisture caused by melting would tend to run down to these ridges, possibly to refreeze there when temperatures fell.

It seemed possible that the general pattern of under-surface ablation polygons might have been caused by air turbulence, especially over the rocks and rough water surface of the stream. The sharp edges of the polygons would experience melting under the influence of warm winds, and would hence offer the most likely lodging places for dirt.

A square on the roof of the stream's tunnel was scraped clear of ablation polygons to leave a flat surface. Two days later, after some wind, the ablation polygons were reappearing, though no dirt had lodged either on their ridges or in their hollows. It would thus appear 
that the dirt is not an essential feature in the formation of ablation polygons, but that its presence augments and accentuates the shapes.

MS. received 12 June 1962 and in revised form 24 February 1965

\section{REFERENCES}

Ball, F. K. 1954. Dirt polygons on snow. Weather, Vol. 9, No. 1o, p. 322-23.

Bout, P. 1957. Les cônes de poussières des glaciers islandais. Revue de Géomorphologie Dynamique, An. 7, Nos. 7-8, p. 97-109.

Richardson, W. E., and Harper, R. D. M. 1957. Ablation polygons on snow-further observations and theories. Journal of Glaciology, Vol. 3, No. 21, p. 25-27.

Sjödin, E. 1957. Meteorological observations on the Mikka glacier in the Sarek massif, Swedish Lappland, during the summer of 1956. Geografiska Annaler, Arg. 39, Ht. 1, p. 54-83.

Swithinbank, C. 1950. The origin of dirt cones on glaciers. Journal of Glaciology, Vol. I, No. 8, p. 46 I-65. 